THE FAMILIAL CONTEXT OF CHILDREN'S CREATIVITY: PARENTING STYLES AND THE CLIMATE FOR CREATIVITY IN PARENT-CHILD

\author{
RELATIONSHIP
}

Dorota Maria JANKOWSKA ORCID: http://orcid.org/0000-0003-3758-5914 1

and

Jacek GRALEWSKI ORCID: https://orcid.org/0000-0002-5089-7755 1

${ }^{1}$ The Maria Grzegorzewska University, Department of Educational Sciences, The Maria Grzegorzewska University, 40 Szczesliwicka St., 02-353 Warsaw, Poland

Corresponding author: Dorota Maria Jankowska, dorotamariajankowska@gmail.com

\begin{abstract}
The purpose of this study was to explore the relationship between dimensions of a constructive parenting style, (i.e. parental acceptance and autonomy granting) factors of the climate for creativity in parent-child relationships (encouragement to experience novelty and variety, encouragement of nonconformism, support of perseverance in creative efforts, and encouragement to fantasize), and parents' visual mental imagery. 313 parents children between 6 and 12 years of age participated in the study. The results indicated that (a) a constructive parenting style was positively related to three of four factors of the climate for creativity in the parent-child relationships, i.e. encouragement to experience novelty and variety, support of perseverance in creative efforts, and encouragement to fantasize in the parent-child relationship; (b) parents' level of vividness of mental imagery was positively related with both parental acceptance of child and autonomy support as well as components of climate for creativity in parent-child relationship; (c) mothers scored significantly higher than fathers in exhibiting acceptance of a child; (d) parents' gender played an important role in the relations between dimensions of constructive parenting style and factors of climate for creativity in parent-child relationships. Findings were discussed in terms of the implications for further research and theory development in the area of family influences on the development of children's creativity.

Keywords: climate for creativity in parent-child relationship, creativity, creative home environment, parenting styles, visual mental imagery
\end{abstract}

\title{
Funding
}

This study was supported by the funding obtained from National Science Centre (UMO-2017/27/B/HS6/00592) for Dorota Maria Jankowska.

\section{Disclosure statement}

\section{Author contributions}

Dorota Maria Jankowska: Conceptualization, Methodology, Investigation, Writing - original draft, Writing review \& editing. Jacek Gralewski: Conceptualization, Methodology, Formal analysis, Writing - original draft, Writing - review \& editing. 


\section{Introduction}

The family as a basic social institution plays a crucial role in child`s development, including creativity (e.g. Jankowska \& Karwowski, 2019; Koestner, Walker, \& Fichman, 1999; Miller \& Gerard, 1979; for a review;; Pang, Lu, Long, Wang, \& Lin, 2020). Many studies were conducted on the impact of family relations on creativity (e.g. Gardner \& Moran, 1990; Lebuda, \& Csikszentmihalyi, 2020; Michel \& Dudek, 1991), but there is still a lack of research on a specific climate for creativity in the relationship between a parent and a child (Kwaśniewska \& Lebuda, 2017). Most existing studies on climate for creativity focused on an organizational setting (Ekvall, 1996; Hunter, Bedell, \& Mumford, 2007; for a review) and school environment (e.g. Ekvall \& Ryhammar, 1998; Furman, 1998; Kallestad, Olweus, \& Alsaker, 1998; Karwowski, 2011). It is proven that parents who support their child's creativity create a specific climate within the home, i.e. they encourage to experience novelty, variety, and nonconformism, inspire to fantasize and creative thinking, and support for perseverance in creativity efforts (Kwaśniewska, Gralewski, Witkowska, Kostrzewska, \& Lebuda, 2018). On the other hand, it has also been proved that the parenting style characterized by parental warmth, acceptance of child, and autonomy support plays a vital role in a child's creativity development (e.g. Fan \& Zhang, 2014; Grolnick, Gurland, DeCourcey, \& Jacob, 2002; Lim \& Smith, 2008; Tennent \& Berthelsen, 1997). In fact, both in the case of research on parenting styles and research on the climate for creativity in the family context, the analyses concern parental practices. The only difference between the two cases is that in the first one the analyses are at a general-domain level, which means that they relate to a wide range of behaviors related to parenthood, while analyses of the climate for creativity are domain-specific, i.e. they are associated with parents' behavior of supporting their child's creativity. Interestingly, the relationship between parenting styles and parental behaviors that constitute the climate of creativity in a family context has not been examined yet. However, in other areas of parental research (see e.g. parental self-efficacy; Wittkowski, Garrett, Calam, \& Weisberg, 2017), such levels of measurement and analysis have already been established. Additionally, parental styles analysis was assigned to a broader category of research into the climate in family life and the quality of home environment (Olszewski, Kulieke, \& Buescher, 1987; for a review). To fill this gap in empirical literature on creative home environment, the present study was designed as likely the first attempt to investigate the link between the dimensions of parental styles and climate for creativity in parent-child relationships. It also takes into account vividness of visual mental imagery as parents' creative potential (e.g. González, Campos, \& Pérez, 1997; Palmiero, Cardi, \& Belardinelli, 2011). Thus, through the findings of this study it is hoped that this might lead to a better understanding of parental behaviors that build a creative home environment. It is important 
because parents who value creativity and provide a creative home environment are more likely to nurture children's creativity (Pugsley \& Acar, 2018).

\section{Fostering Creativity at Home}

Research on family factors related to the development of children's talent and creativity can be divided into four main categories: (1) family structural characteristics, such as socioeconomic status, family size, family structure, sibling constellations or number of siblings; (2) family climate or environment that refers to the dimensions of atmosphere within the home and includes parenting styles and attitudes, behaviors and practices, as well as emphasis on structure, and rules for family life; (3) values espoused by parents regarding success and achievement; and (4) values enacted/modelled, such as providing cultural experiences (see e.g. Olszewski et al., 1987 for a review). Both analyses of parenting styles and family climate in parent-child relationship refer to the second of these categories. These characteristics capture the quality of home environment and cover parental behaviors and structures intended to realize basic functions for optimal children's development, including safety/sustenance, stimulation, socioemotional support, structure, and surveillance (Bradley \& Corwyn, 2004).

In the field of creativity, despite the long history of studies regarding the influence of family factors on realization of children's creative potential, research on the role of home (family) environmental factors is still quite limited (e.g. Deng,Wang, \& Zhao, 2016; Jankowska \& Karwowski, 2019). Early theoretical perspectives on this subject emphasized that parents who encourage their children to develop and express their own thoughts, feelings, and ideas (autonomy) while maintaining secure attachment and positive emotional bonds (acceptance) create a creative home environment (e.g. Erikson, 1963; Rogers, 1954). Rogers (1954) was likely the first to try to define and describe a creativity-fostering environment. The author outlined two necessary external conditions for creativity: (1) psychological safety - consisting of unconditional acceptance of the child, creating a climate without external judgment, but with emphatic understanding, and (2) psychological freedom that is based on personal autonomy and permission to engage in unrestrained symbolic expression. As a result, through a gradual process of becoming, the child can learn about him- or herself and others, using this newfound knowledge to engage in creativity and growth. Harrington and colleagues (1987) tested Rogers' (1954) theory of creativityfostering environments in the family context. In a longitudinal study, they found significant relationships between parenting behaviors suggested by Rogers and creative potential at both preschool stage and seven years later in early adolescents years. When controlled for the effects of sex, intelligence, and preschool creativity, these results were still significant. 
Further empirical studies that examined the influence of a family environment on children's creativity also revealed a relationship between creativity and parenting style, which is conceptualized as a constellation of parents' attitudes and behaviors toward children and an emotional climate in which the parents' behaviors are expressed (Darling \& Steinberg, 1993). Baumrind (1967) and later Maccoby and Martin (1983) described two dimensions in parenting styles: (1) demandingness - direct confrontations, monitoring, and consistent, contingent discipline, and (2) responsiveness - affective warmth, reciprocity in parent-child interactions, acceptance, clear communication, and attachment. These dimensions allowed for identifying four types of parenting styles: authoritative (when parents show high levels of demandingness and responsiveness), permissive (low levels of demandingness and high levels of responsiveness), authoritarian (high levels of demandingness and low levels of responsiveness), and neglectful (low levels of both dimensions). More recent studies on parenting styles more frequently focus on parenting dimensions, defined as "the features, the qualities, the descriptive scheme used to capture the nature of parenting" (Skinner, Johnson, \& Snyder, 2005, p. 184). In this approach, parental warmth, control, and structure are most commonly studied parenting dimensions (Power, 2013; Skinner et al., 2005). In literature, a parenting style is also categorized as constructive (supportivepositive) and destructive (harsh-negative) in terms of these dimensions (e.g. Darling \& Steinberg, 1993; Simons, Whitbeck, Conger, \& Melby, 1990). This approach emphasizes a type of parenting that includes both emotional (e.g. affection, warmth) and behavioral (e.g. monitoring and control) components. Constructive parenting includes multiple aspects of parenting, such as parental warmth and involvement, acceptance, autonomy granting, parental support, clear communication, appropriate monitoring and supervision, consistent discipline, and authoritative parenting. These parenting behaviors might be labeled as constructive parenting, because they support and contribute to positive child development. Destructive parenting refers to the behaviors that involve hostility, rejection, coercion, punishments, inconsistent discipline, authoritarian parenting, and permissive parenting (e.g. Kawabata, Alink, Tseng, van Ijzendoorn, \& Crick, 2011; Simons et al., 1990).

In this study, we categorize a parenting style into five dimensions: acceptance of child, autonomy support, over-protecting, over-demanding, and lack of consequence (Plopa, 2008), which express parental warmth and control. The dimensions of acceptance of child and autonomy support create a constructive (desirable) parental style, which we assume will be associated with the climate for creativity in parent-child relationship. The dimension of acceptance stresses unconditional acceptance of a child as a person, which means respecting and loving the child without regard for her or his positive or negative traits and its understructure of the parental warmth dimension (Fijałkowska \& Bielawska-Batorowicz, 2019; Skinner et al., 2005). An accepting 
parent creates the atmosphere of a free exchange of feelings and thoughts, trust towards the world and people, safety, and providing a sense of support. These parents are open to various forms of support, without imposing themselves. This attitude of autonomy towards children is expressed by allowing them to single-handedly explore the world, e.g. by solving problems, learning from mistakes, and independent decision-making. These parents show rational tolerance for mistakes made by their child. If necessary, they provide the child with advice, help or discussion. Parents who display an attitude of autonomy act in a flexible way and adapt to their children's developmental needs. Parents evaluated as excessively intervening in a children's life (with excessive protection) are interested in each, even the smallest, manifestation of a child's activity. They interfere in children's personal affairs, want to know everything about them, and try to surround them with constant care. They receive signs of autonomy in children's behavior with fear and anxiety. Excessive demands are associated with demanding unconditional obedience. Such parents limit their children's autonomy through numerous bans, orders, and punishments. Those parents are described as strict with a punitive attitude. They have a vision of their children's future and rigidly demand its imposition. The attitude of inconsistency means that the relationship between a parent and a child is variable, depending on temporary mood, mood and other personal matters, but not necessarily related to family life. This makes it impossible to build a calm, friendly atmosphere in the family (Fijałkowska \& Bielawska-Batorowicz, 2019; Plopa, 2008; Puchalska-Wasyl \& Jankowski, 2020).

Our conceptualization of the climate for creativity in parent-child relationship is defined as "parents' overall relatively constant behavioral pattern that helps the child acquire a mindset, attitudes, personal qualities, and skills necessary for creativity" (Kwaśniewska et al., 2018, p.14). The climate for creativity in parent-child relationship focuses on empirically derived factors, namely encouragement to experience novelty, variety, and nonconformism, inspiration to fantasize and creative thinking, and support for perseverance in creativity efforts (Kwaśniewska et al., 2018; Kwaśniewska \& Lebuda, 2017). The factors identified in this concept primarily encompass an attitude that promotes children's autonomy and acceptance for their creative endeavors. Encouragement to Experience Novelty and Variety means parents' willingness to put their children in new situations and encouraging them to think and act out of the box. Encouragement of Nonconformism is about allowing parents to follow their children's own paths, including breaking established social norms and crossing their boundaries. Support of Perseverance in Creative Efforts is associated with parents' willingness to support their children in their creative activity, appreciation of their children's ideas, and motivating them to continue to act even if they fail. Encouragement to Fantasize is about encouraging children to think creatively and use their imagination (Kwaśniewska et al., 2018; Kwaśniewska \& Lebuda, 2017). 


\section{Association between Dimensions of Parenting Styles and Factors of Climate for Creativity in Parent-Child Relationship}

The concept of creativity is a broad construct that has been defined and operationalized in numerous ways in various studies. Developmental psychologists, who focus in their work on opportunities for developing creative potential, emphasize the role of children's experience of novelty and variety in the development of little-c and mini-c creativity (Beghetto \& Kaufman, 2007; Runco, 2003). Undoubtedly, children's autonomy in action is the basis for such impacts. Wide knowledge of the world and a variety of information from different fields constitute a cultural capital, which is important for the development of children's creativity (Kwaśniewska et al., 2018). Allowing children to experiment, to search creatively, to solve problems on their own, seems to be the best way to support the development of creative (divergent) thinking, with several important characteristics, namely: (1) fluency, understood as the ability to come up with many ideas; (2) flexibility, or the ability to create solutions that are qualitatively diverse; (3) originality, responsible for producing rare and untypical ideas; and (4) elaboration - the ability to develop ideas (Guilford, 1967). Moreover, it has been proven that creative people grew up in families that encouraged their children to experience novelty and variety (Tennent \& Berthelsen, 1997). Thus, promoting the development of children's creativity is linked to allowing them to be independent and take risks in new and unfamiliar ideas (Michel \& Dudek, 1991). Also, families of eminent and professional creators provided them with intellectual stimulation, encouraged exploration of the environment, strengthened the autonomy of thinking, supported new interests, and granted their children the right to make autonomic choices (e.g. Goertzel, Goertzel, Goertzel, \& Hansen, 2004; Gute, Gute, Nakamura, \& Csikszentmihályi, 2008). Based on these reports, we formulated the following hypotheses:

H1a and H1b: It is assumed that in the parent-child relationship, a constructive parenting style [i.e. parental acceptance of child (HIa) and autonomygranting (H1b)] would be positively related to the encouragement to experience novelty and variety.

Many researchers view the concept of creativity through the prism of personality traits that include independence (e.g. Batey \& Furnham, 2006; Nickerson, 1999; Stavridou \& Furnham, 1996). Autonomy and independence have also been tied to creative potential in early developmental and personality literature (e.g. Albert \& Runco, 1989; Cropley, 1967; Rejskind, 1982; Torrance, 1965; Treffinger, 1980). For instance, Wright and Wright (1986) defined creative family environment and stressed three main components, i.e. (1) acceptance and respect for the child, (2) stimulation of independence, and (3) enriched learning environment. Currently, independence with regard to children is defined as a personality dimension marked by nonconformism and low agreeableness as well as readiness to oppose the situationally evoked influence of the group and external factors 
(see The Typological Model of Creativity; Karwowski \& Jankowska, 2016). It has been shown that children's creativity is fostered in a home environment that provides a balance of independence, self-expression, and risktaking in a safe environment (Harrington, 1999). Literature on creativity, also suggested the significance of the combination of parental stimulation and support. It turns out that children who feel supported by their parents and challenged to develop their independence and individuality (autonomy) develop better than those who only receive support or challenge (Howe, 1999; Rathunde, 1996). Also, it has been shown that parental support characterized by acceptance is associated with children's high levels of creativity, autonomy, and low levels of conformity (Fan \& Zhang, 2014). In research on parenting styles, we found that the authoritative parenting style (characterized by high levels of warmth and autonomy encouragement toward the children) is associated with close ties, adaptive control techniques, and appropriate independence. Authoritative parents who encourage their children's autonomy and freedom of thought, interests, and ideas while maintaining positive emotional bonds (acceptance), are more likely to provide environments that actively encourage independence and exploration of ideas (Lim \& Smith, 2008; Mehrinejad, Rajabimoghadam, \& Tarsafi, 2015). This encouragement demonstrates to children their parents' high priority for independence and stimulates efforts along these lines. On the other hand, authoritarian mothers (contrary in terms of warmth and responsiveness) establish restrictive environments that inhibit growing their children's independence by using physical means of discipline and expecting their children not to make mistakes (Tennent \& Berthelsen, 1997). Therefore, the next hypotheses of the present study were:

H2a and H2b: It is assumed that in the parent-child relationship, a constructive parenting style [i.e. parental acceptance of child (H2a) and autonomy granting (H2b)] would be positively related to encouragement of nonconformism.

A persistent attitude is defined as continuously striving and committing to goals regardless of immediate rewards. It is proved that it is one of the most critical creative characteristics of the greatest innovators; one that helped them overcome the lack of resources and all another barriers (Kim, 2016). Also, a longitudinal study of professional creativity points to the importance of persistence for creativity (Helson, Roberts, \& Agronick, 1995). Moreover, most recognized creativity theories include personality traits related to persistence (see e.g. Amabile's componential theory of creativity, 1983, 2012) and point, for example, to the value of perseverance in the face of obstacles (Rank, Pace, \& Frese, 2004). However, in relation to children, it is difficult to talk about a persistent attitude in creative work, which is why emphasis is placed on perseverance in creative efforts, involvement in creative activity in the face of difficulty, challenge or uncertainty, and willingness to take risks 
and learn from mistakes (Robson \& Rowe, 2012). Creativity researchers provide support for the notion that parents play an important role in facilitating their children's creative efforts, which can help lay the foundation for their future creative achievements (Craft, 2006). For instance, Karnes, Shwedel, and Steinberg (1984) found that parents of gifted children more often encouraged their children to be more independent and support their autonomous efforts. In many guides for parents who want to create a creative home environment, one can find suggestions for supporting children's experimentation and creative effort. Examples of such guidance include "encourage your child to get out and explore, to exercise body and mind, to find something new to learn and then really learn it, to be a maverick, to ask questions to be persistent, and to enjoy the process (Foster, 2015, p. 143)". Research on highly creative individuals proved the role of modeling perseverance and achievementproducing work habits (Gute et al., 2008). Parental support of children's creative effort seems to be particularly promising and important because mature perseverance is associated with higher creative achievements (Abuhassàn \& Bates, 2015). Based on these studies, we formulated following the hypotheses:

H3a and H3b: It is assumed that in the parent-child relationship, a constructive parenting style [i.e. parental acceptance of child (H3a) and autonomy granting (H3b)] would be positively related to the support of perseverance in creative efforts.

When creativity is understood as a multi-faceted phenomenon, it is also important to stress that creative imagination is one of the key creative abilities (Karwowski \& Jankowska, 2016). It is therefore not surprising that in the development of childhood creativity, researchers point to the importance of supporting fantasy, i.e. creative imagination (Glăveanu, Karwowski, Jankowska, \& de Saint-Laurent, 2017). According to Vygotsky (1930/2004), imagination helps children to understand the world around them. Operation of imagination depends on the quantity and diversity of experience, so parents should encourage their children to use their creative imagination e.g. through symbolic play, in which children not only reproduce previous experiences but also, with the help of creative (combinatorial) imagination, create new situations and behaviors. Imaginative play is a natural way of supporting children's creative, autonomous expression and a key element of their healthy development (Russ, 2004). In this type of play, children manipulate symbols and representations of objects, recombining ideas and visual mental images according to your own ideas, which is important for their creative exploration. But assumption that children are able to think and act autonomously forms the basis for such support (Jankowska \& Omelańczuk, 2018). Moreover, it has been empirically demonstrated that play combined with the use of fantasy is one of the predictors of adult creativity (Russ, Robins, \& Christiano, 1999). That is why it is so important to encourage fantasizing and creating a climate conducive to imaginative play from an 
early age. Likewise, Tennent and Berthelsen (1997) found that mothers who provide the environment that nurtures children's creativity, also value their curiosity and creative imagination. Accordingly, we hypothesized that:

H4a and H4b: It is assumed that in the parent-child relationship, a constructive parenting style [i.e. parental acceptance of child (H4a) and autonomy granting (H4b)] would be positively related to the encouragement to fantasize.

In literature, the meaning of 'visual mental imagery' is explained by the quality of an individual's visual mental imagery, which is measured in terms of the abilities to generate it, control of the mental images, preference, as well as by the vividness of mental representations (McAvinue \& Robertson, 2007; for a review). Vividness of visual mental imagery, defined as clarity, liveliness of a mental image, and degree of similarity between subjective experience of visual imagery and corresponding perceptual experience (D'Angiulli \& Reeves, 2007), is the most commonly measured dimension of imagery ability (Kihlstrom, Glisky, Peterson, Harvey, \& Rose, 1991), also in creativity literature (e.g. LeBoutillier \& Marks, 2003; for a review). There is plenty of empirical evidence to show that vividness of images and creativity (mainly creative thinking) are interconnected $(\mathrm{r}=.2-.4)$, which is confirmed by a meta-analysis that sums up these studies (LeBoutillier \& Marks, 2003). We assume that vividness of mental images, defined as a parents' creative potential, can help parents understand, visualize, and ultimately create opportunities for creativity in the home environment.

Although literature on creativity suggests existence of relationships between parents' behaviors and climate for creativity in the home environment, most of such studies exclusively examined maternal parenting characteristics (e.g. Kwaśniewska et al., 2018; Michel \& Dudek, 1991; Tennent \& Berthelsen, 1997). Thus, fathers continue to be clearly underrepresented in this research. Moreover, even if mothers and fathers are involved in the study, the researchers do not analyze gender differences within the indicated range (see e.g. Lim \& Smith, 2008). Meanwhile, studies on the content of parental interactions show that both parents report behaviors connected to the parental warmth (acceptance) dimension, but these behavioral expressions are more frequent in mother-child than in father-child dyads (Russell \& Russell, 1987). And although today fathers are caring for their children more than in the past (Sayer, Bianchi, \& Robinson, 2004), mothers still spend a greater share of time taking care of children than fathers (e.g. Craig, 2006; McBride \& Mills, 1993; Mehall, Spinrad, Eisenberg, \& Gaertner, 2009). Mothers tend to guide, teach, and engage in empathic conversations when interacting with their children (John, Halliburton, \& Humphrey, 2013). Fathers are more likely to involve in physical and outdoor play interactions, educational and recreational activities more than any other kinds of 
caring (e.g. Craig, 2006; Craig \& Mullan, 2011; Mehall et al., 2009). Importantly, during play fathers are more likely than mothers to encourage their children to take risks and initiative in unfamiliar situations, overcome obstacles, and explore unconventional play (John et al., 2013; Kromelow, Harding, \& Touris, 1990). Supporting this idea, Grossman et al. (2002) made the point that the role of the father as play partner and a gently challenging companion during creative exploration of the world may be particularly important in supporting the child's autonomy, especially in preschool and early school years. In this paper, we analyze maternal as well as paternal parenting styles in terms of differential impacts of parents' gender in creating climate for creativity in home environment.

\section{The Present Study}

The principal purpose of the present study was to explore the relationship between dimensions of constructive parenting styles, (i.e. parental acceptance and autonomy granting), and factors of the climate for creativity in parent-child relationships, namely encouragement to experience novelty and variety, encouragement of nonconformism, support of perseverance in creative efforts, and encouragement to fantasize, as well as parents' vividness of mental imagery. Based on the literature review, we formulated eight detailed research hypotheses (H1a, H1b, H2a, H2b, H3a, H3b, H4a, H4b), which we presented in the theoretical introduction. Moreover, we formulated the following two research questions:

1. Is there a relationship between parents' level of vividness of mental imagery, defined as a parent's creative potential and climate for creativity in parent-child relationship?

2. Does parents' gender differentiate the structure of the relationships between dimensions of constructive parenting style and factors of the climate for creativity in parent-child relationship?

To the best of our knowledge, the present study is the first research on associations between dimensions of parenting style and factors of climate for creativity in the family context.

\section{Method}

\subsection{Participants}

Data from 313 parents ( $49.8 \%$ of whom were mothers and $50.2 \%$ of fathers) were analyzed. Respondents had between 1 and 4 children $(M=1.89 ; \mathrm{SD}=0.66)$, of which $33.5 \%$ had one, $47.6 \%$ two, $15 \%$ three, and $3.8 \%$ four. The respondents were between 26 and 54 years of age, with an average of $\mathrm{M}=38.97$ and $\mathrm{SD}=6.37$. All participants were Polish. $36.4 \%$ of them came from cities with a population of over 100,$000 ; 27.5 \%$ from cities with a population between 20,000 and 100,$000 ; 10.9 \%$ from cities with a population under 20,000 ; and $25.2 \%$ lived in rural areas. The majority of survey participants had higher (54\%) or secondary (45\%) education, while 
only $1 \%$ had primary education completed. The majority of participants (58.3\%) declared very good financial situation, which allows them to satisfy all their needs without sacrifices. $31.4 \%$ claimed that they live frugally to satisfy all their needs, while $10.3 \%$ claimed that their financial situation allows them to satisfy only basic needs and requires constant saving.

\subsection{Measures}

The Climate for Creativity in Parent-Child Relationship. The Climate for Creativity in Parent-Child Relationship Questionnaire (CCP-CRQ; Kwaśniewska et al., 2018) is a 24-item, self-administered instrument measuring four dimensions of parental behaviors that promote the climate for creativity in parent-child relationships: Encouragement to Experience Novelty and Variety (e.g. I try to suggest to my child unconventional ways to solve problems), Encouragement of Nonconformism (e.g. It is important to me that my child is always being polite, revised item), Support of Perseverance in Creative Efforts (e.g. I always value my child's ideas even if they are far from perfection), and Encouragement to Fantasize (e.g. I encourage my child to fantasize). Each scale consists of six items. Using a seven-point response scale (1 - Entirely Disagree, 4 Neither Agree nor Disagree, 7 - Entirely Agree), participants rate the degree of their agreement with each item. Each scale of the CCP-CRQ has acceptable reliability. The values of internal consistency determined by the conservative method of Cronbach's $\alpha$ range in this study were acceptable: encouragement to experience novelty and variety $\alpha=.81$, encouragement of nonconformism $\alpha=.77$, support of perseverance in creative efforts $\alpha=$ .89 , and encouragement to fantasize $\alpha=.75$.

Parenting Styles. The Parental Attitudes Scale (KPR; Plopa, 2008) characterize parenting styles towards children according to five dimensions: Acceptance of a Child (e.g. I often try to make it clear to my child that I love him), Autonomy Granting (e.g. I agree that my child may make different choices depending on his age), Excessive Protecting (e.g. I always want to know where my child is and what my child is doing), Excessive requirements (e.g. I demand absolute obedience from the child), and Inconsistency (e.g. When I'm nervous, it's hard to predict how I'll behave towards my child). Each dimension has 10 statements. For all dimensions, a 5point response scale is used ( 1 -I am definitely not like that and I don't act like that; 3 - I have doubts if I am like that and I behave like that; 5 -I'm definitely like that and I behave like that). The Cronbach's alpha coefficients for the KPR in this study were average: acceptance $\alpha=.91$, excessive requirements $\alpha=.89$, autonomy $\alpha=.79$, incocnsistency $\alpha=91$, and excessive protecting $\alpha=.85$.

Vividness of Mental Imagery. The Vividness of Visual Imagery Questionnaire (VVIQ; Marks, 1973) is the questionnaire that provides a global assessment of the vividness of mental imagery. The VVIQ consists of 16 
items in four groups of 4 . The participant is invited to consider the mental image about specific scenes and situations (e.g. Visualize a rising sun. Consider carefully the picture that comes before your mind's eye). For each image, participants indicate how vivid the four items relating to that image are (e.g. The sun rising above the horizon into a hazy sky) by providing a rating on a scale from one (Perfectly clear and vivid as real seeing) to five (No image at all, you only "know" that you are thinking of the object). Internal consistency reliability of the VVIQ is high, usually with alpha coefficients around 90 (e.g. Burton, 2003; Campos \& Pérez-Fabello, 2009), in this study $\alpha=.96$.

\subsection{Procedure}

Research was conducted with the use of the Computer Assisted Web Interview method based on original questionnaires in an electronic form. In this study, only one parent per family contributed data and all participants had one or more children between 6 and 12 years of age. If the household had more than one child at that age, only one was selected as the target child for the study. All parents who agreed to participate in the survey were included (with the assumption that a half of the sample will be made up of fathers). Parents were also informed about data confidentiality and they provided consent to process personal data. Protocol and procedure of the study were accepted by the Institutional Review Board of the 1st author's university.

\section{Data analysis}

In first step, descriptive statistics and bivariate correlations were computed. The goal of these analyses was to perform initial verification of the hypotheses we formulated and first research question. Next - due to the special role of parents' gender in further analyses - a MANOVA was conducted to examine whether and to what extent the measured characteristics differed for mothers and fathers. In order to respond to the research question no. 2, in the last step we performed a series of hierarchical regression analyses for the entire sample, and separately among mothers and fathers, to test the moderating effects of parents gender.

\section{Results}

Descriptive statistics and intercorrelations between individual variables controlled in the study are presented in Table 1.

The structure of relations between individual scales and the Parental Attitudes Scale (KPR; Plopa, 2008) confirms the anticipated division into constructive (supportive-positive) and destructive (harsh-negative) parenting styles. Consistently, the constructive parenting style is made up of the dimensions of acceptance and autonomy, which remain in a strong and positive correlation $(r=.64)$. At the same time, the dimension of 
acceptance remains in a weak and negative correlation with the dimension of inconsistency $(r=-.29)$ as well as a weak but positive correlation with the dimension of excessive protecting $(r=.24)$. In turn, destructive parenting style is made up of the dimensions of excessive requirements, incocnsistency and excessive protecting, which are strongly and positively correlated. The dimension of excessive requirements strongly correlated with the dimension of inconsistency $(r=.70)$ as well as excessive protecting $(r=.55)$. In turn, the dimension of inconsistency was averagely correlated with the dimension of excessive protecting $(r=.42)$. Characteristically, none of the dimensions significantly correlated with the attitude of autonomy.

Also, individual dimensions of parental behaviors that promote the climate for creativity in the parentchild relationships remained in positive correlations that fell between $r=.35$ and $r=.79$, whereby the weakest correlation was observed between encouragement of nonconformism and encouragement to fantasize, and the strongest between encouragement to fantasize and encouragement to experience novelty and variety.

$$
\text { --- Insert Table } 1 \text { here --- }
$$

Table 1

Descriptive statistics and intercorrelations between study variables

\begin{tabular}{|c|c|c|c|c|c|c|c|c|c|c|c|}
\hline & Variable & 1 & 2 & 3 & 4 & 5 & 6 & 7 & 8 & 9 & 10 \\
\hline 1 & $\begin{array}{l}\text { Acceptance of a } \\
\text { child }\end{array}$ & 1 & & & & & & & & & \\
\hline 2 & $\begin{array}{l}\text { Excessive } \\
\text { requirements }\end{array}$ & .03 & 1 & & & & & & & & \\
\hline 3 & $\begin{array}{l}\text { Autonomy } \\
\text { granting }\end{array}$ & $.64^{*}$ & -.03 & 1 & & & & & & & \\
\hline 4 & Inconsistency & $-.29 *$ & $.70^{*}$ & -.08 & 1 & & & & & & \\
\hline 5 & $\begin{array}{l}\text { Excessive } \\
\text { protecting }\end{array}$ & $.24 *$ & $.55^{*}$ & .09 & $.42^{*}$ & 1 & & & & & \\
\hline 6 & VVIQ & $.37^{*}$ & .01 & $.26^{*}$ & $-.13 *$ & -.01 & 1 & & & & \\
\hline 7 & $\begin{array}{l}\text { Encouragement to } \\
\text { experience novelty } \\
\text { and variety }\end{array}$ & $.40 *$ & $-.16^{*}$ & $.33 *$ & $-.27 *$ & -.06 & $.32 *$ & 1 & & & \\
\hline 8 & $\begin{array}{l}\text { Encouragement of } \\
\text { nonconformism }\end{array}$ & .05 & $.30^{*}$ & -.07 & .05 & $.25^{*}$ & $.19 *$ & $.38 *$ & 1 & & \\
\hline 9 & $\begin{array}{l}\text { Support of } \\
\text { perseverance in } \\
\text { creative efforts }\end{array}$ & $.49 *$ & $-.22 *$ & $.39 *$ & $-.38^{*}$ & -.01 & $.28 *$ & $.76^{*}$ & $.42 *$ & 1 & \\
\hline 10 & $\begin{array}{l}\text { Encouragement to } \\
\text { fantasize }\end{array}$ & $.28 *$ & $-.13^{*}$ & $.28 *$ & $-.18^{*}$ & -.04 & $.27 *$ & $.79 *$ & $.35^{*}$ & $.69^{*}$ & 1 \\
\hline & $M$ & 4.24 & 3.03 & 3.74 & 2.54 & 3.19 & 119.57 & 5.33 & 5.10 & 5.76 & 5.26 \\
\hline & $S D$ & 0.65 & 0.75 & 0.55 & 0.87 & 0.74 & 21.33 & 0.85 & 0.87 & 0.80 & 0.83 \\
\hline
\end{tabular}

Legend: VVIQ - Vividness of Visual Imagery Questionnaire $* p<.05$.

Bivarite correlations confirmed that hypotheses $\mathrm{H} 1 \mathrm{a}, \mathrm{H} 3 \mathrm{a}$ and $\mathrm{H} 4 \mathrm{a}$ were right. According to those hypotheses, parental acceptance of a child would be positively related to the encouragement to experience novelty and variety $(r=.40 ; p<.05)$, support of perseverance in creative efforts $(r=.49 ; p<.05)$, and encouragement to fantasize in the parent-child relationship $(r=.28 ; p<.05)$. However, hypothesis $\mathrm{H} 2 \mathrm{a}$, which 
assumed a correlation between parental acceptance of child and encouragement of nonconformism $(r=.05 ; p>$ $.05)$, did not find its confirmation.

Hypotheses $\mathrm{H} 1 \mathrm{~b}, \mathrm{H} 3 \mathrm{~b}$ and $\mathrm{H} 4 \mathrm{~b}$ were also confirmed. According to them, parental autonomy granting would be positively related to the encouragement to experience novelty and variety $(r=.33 ; p<.05)$, support of perseverance in creative efforts $(r=.39 ; p<.05)$, and encouragement to fantasize in the parent-child relationship $(r=.28 ; p<.05)$. However, hypothesis $\mathrm{H} 2 \mathrm{~b}$, which anticipated a positive correlation between parental autonomy of a child and encouragement of nonconformism in the parent-child relationship $(r=-.07 ; p>.05)$ did not find its confirmation.

Additionally, we noted weak and negative correlations between parental excessive requirements and the encouragement to experience novelty and variety $(r=-.16 ; p<.05)$, support of perseverance in creative efforts $(r$ $=-.22 ; p<.05)$, and encouragement to fantasize in the parent-child relationship $(r=-.13 ; p<.05)$, as well as a weak but positive correlation of this dimension with encouragement of nonconformism $(r=.30 ; p<.05)$. In turn, parental incocnsistency strongly and negatively correlated with support of perseverance in creative efforts $(r=-$ $.38 ; p<.05)$, as well as weakly and negatively correlated with encouragement to experience novelty and variety $(r=-.27 ; p<.05)$, and encouragement to fantasize in the parent-child relationship $(r=-.18 ; p<.05)$, while parental excessive protecting weakly but positively correlated with encouragement of nonconformism in the parent-child relationship $(r=.25 ; p<.05)$.

Parents' level of vividness of mental imagery remained in weak and positive, but statistically significant relations $(p<.05)$ with individual components of the climate for creativity in parent-child relationship, which amounted to: $r=.32$ for encouragement to experience novelty and variety, $r=.19$ for encouragement of nonconformism, $r=.28$ for support of perseverance in creative efforts and $r=.27$ for encouragement to fantasize. This confirms our suppositions that creative potential can help parents create opportunities for creativity in the home environment. Moreover, parents' level of vividness of mental imagery remained in positive and statistically significant correlations with parental acceptance of a child $(r=.37 ; p<.05)$ and parental autonomy granting $(r=.26 ; p<.05)$, while weakly and negatively correlating with parental inconsistency $(r=-.13 ; p<.05)$. The dimensions of parental excessive requirements $(r=.01 ; p>.05)$ as well as excessive protecting $(r=. .01 ; p>.05)$ did not correlate with parents' creative potential (i.e. vividness of mental imagery).

The MANOVA revealed existence of two statistically significant differences between mothers' and fathers' characteristics $[F(10,302)=3838.91 ; p<.001]$. According to them, mothers are characterized by a 
significantly higher intensity of acceptance of a child than are fathers [mothers: $M=4.35, S D=0.66$, fathers: $M$ $=4.13 ; S D=0.61, F(1,311)=9.30 ; p<.001 ; d=.34]$ and excessive protecting $[$ mothers: $M=3.30 ; S D=0.78$, fathers: $M=3.08 ; S D=0.67, F(1,311)=7.72 ; p<.001 ; d=.31]$. However, no statistically significant differences were noted between mothers and fathers in the remaining variables controlled in this study, namely parental excessive requirements [mothers: $M=3.00 ; S D=0.81$, fathers: $M=3.06 ; S D=0.69, F(1,311)=0.55$; $p>.05 ; d=.08$ ], autonomy [mothers: $M=3.74 ; S D=0.59$, fathers: $M=3.74 ; S D=0.51, F(1,311)=0.02 ; p>$ $.05 ; d=.02$ ], incocnsistency [mothers: $M=2.57 ; S D=0.92$, fathers: $M=2.50 ; S D=0.81 F(1,311)=0.66 ; p>$ $.05 ; d=.09$ ], level of vividness of mental imagery [mothers: $M=118.96 ; S D=23.35$, fathers: $M=120.18 ; S D=$ $19.17, F(1,311)=0.26 ; p>.05 ; d=.06]$, encouragement to experience novelty and variety [mothers: $M=5.30$; $S D=0.82$, fathers: $M=5.37 ; S D=0.87, F(1,311)=0.54 ; p>.05 ; d=.08]$, encouragement of nonconformism [mothers: $M=5.06 ; S D=0.88$, fathers: $M=5.14 ; S D=0.86, F(1,311)=0.67 ; p>.05 ; d=.09$ ], support of perseverance in creative efforts [mothers: $M=5.81 ; S D=0.79$, fathers: $M=5.71 ; S D=0.82, F(1,311)=1.23$; $p>.05 ; d=.12$ ] and encouragement to fantasize [mothers: $M=5.24 ; S D=0.84$, fathers: $M=5.28 ; S D=0.81, F$ $(1,311)=0.18 ; p>.05 ; d=.05]$.

In the next step, we conducted a series of hierarchical regression analyses (Table 2). In each of them, we predicted consecutive dimensions of the climate for creativity in parent-child relationships. We introduced independent variables in two stages; the first variable was dimensions of a constructive parenting style, and the second was dimensions of destructive parenting style. Such a solution made it possible for us to determine percentages of explained variance $\left(\mathrm{R}^{2}\right)$ of individual dimensions of the climate for creativity shared by the constructive and destructive parenting style components, thanks to which it then became possible to identify the one that plays a key role in shaping conditions for parents to support their children's creativity. Because a number of variables correlated, we controlled the level of multicollinearity (see Aiken \& West, 2001) for each model. In each model we tested, the Variance Inflation Factors were below 2.9, which showed that the level of multicollinearity (Hair, Anderson, Tatham, \& Black, 1995) was permissible.

Results of regression analyses for the entire sample confirmed validity of hypotheses H1a, H1b, H3a, $\mathrm{H} 3 \mathrm{~b}, \mathrm{H} 4 \mathrm{a}$, and $\mathrm{H} 4 \mathrm{~b}$. According to them, a constructive parenting style, made up of the dimensions of acceptance of a child and autonomy granting, positively correlated with three of four components of the climate for creativity in parent-child relationships, namely: (1) encouragement to experience novelty and variety, (2) support of perseverance in creative efforts, and (3) encouragement to fantasize. However, hypotheses $\mathrm{H} 2 \mathrm{a}$ and $\mathrm{H} 2 \mathrm{~b}$ were 
rejected, because components of the constructive parenting style were not statistically significantly related to encouragement of nonconformism. 
Table 2

Regression analyses

\begin{tabular}{|c|c|c|c|c|c|c|c|c|c|c|c|c|}
\hline \multirow[b]{2}{*}{ Predictors } & \multicolumn{3}{|c|}{$\begin{array}{c}\text { Encouragement to experience novelty } \\
\text { and variety }\end{array}$} & \multicolumn{3}{|c|}{$\begin{array}{c}\text { Encouragement } \\
\text { of nonconformism }\end{array}$} & \multicolumn{3}{|c|}{$\begin{array}{l}\text { Support of perseverance } \\
\text { in creative efforts }\end{array}$} & \multicolumn{3}{|c|}{$\begin{array}{c}\text { Encouragement } \\
\text { to fantasize }\end{array}$} \\
\hline & $\begin{array}{c}\text { Whole } \\
\text { sample } \\
\beta\end{array}$ & $\begin{array}{c}\text { Mothers } \\
\beta\end{array}$ & $\begin{array}{c}\text { Fathers } \\
\beta\end{array}$ & $\begin{array}{c}\text { Whole } \\
\text { sample } \\
\beta\end{array}$ & $\begin{array}{c}\text { Mothers } \\
\beta\end{array}$ & $\begin{array}{c}\text { Fathers } \\
\quad \beta\end{array}$ & $\begin{array}{c}\text { Whole } \\
\text { sample } \\
\beta\end{array}$ & $\begin{array}{c}\text { Mothers } \\
\beta\end{array}$ & $\begin{array}{c}\text { Fathers } \\
\beta\end{array}$ & $\begin{array}{c}\text { Whole } \\
\text { sample } \\
\beta\end{array}$ & $\begin{array}{c}\text { Mothers } \\
\beta\end{array}$ & $\begin{array}{c}\text { Fathers } \\
\quad \beta\end{array}$ \\
\hline
\end{tabular}

Step 1: Dimensions of constructive parenting style

\begin{tabular}{|c|c|c|c|c|c|c|c|c|c|c|c|c|}
\hline $\begin{array}{l}\text { Acceptance } \\
\text { of a child }\end{array}$ & $.28 * *$ & $.47 * * *$ & $.21^{*}$ & .08 & .09 & -.02 & $.32 * * *$ & $.39 * * *$ & $.35 * * *$ & $.17^{*}$ & $.23^{*}$ & .14 \\
\hline $\begin{array}{l}\text { Autonomy } \\
\text { granting }\end{array}$ & $.14^{*}$ & .05 & $.26^{*}$ & .05 & .09 & -.01 & $.16^{*}$ & .02 & $.26^{*}$ & $.18^{*}$ & .06 & $.28 * *$ \\
\hline$R_{\text {corrected }}^{2}$ & $.16^{* * *}$ & $.19 * * *$ & $.19 * * *$ & $.02 *$ & $.03 *$ & .01 & $.25 * * *$ & $.22 * * *$ & $.29 * * *$ & $.09 * * *$ & $.06^{* *}$ & $.131 * * *$ \\
\hline
\end{tabular}

Step 2: Dimensions of destructive parenting style

\begin{tabular}{|c|c|c|c|c|c|c|c|c|c|c|c|c|}
\hline $\begin{array}{l}\text { Excessive } \\
\text { requirements }\end{array}$ & -.04 & -.12 & -.06 & $.48 * * *$ & $.53 * * *$ & $.40 * *$ & -.08 & -.14 & -.04 & -.09 & -.10 & -.15 \\
\hline Inconsistency & -.10 & -.05 & -.05 & $-.39 * * *$ & $-.49 * * *$ & $-.23 *$ & $-.23 * *$ & $-.28^{*}$ & -.13 & -.04 & -.05 & .04 \\
\hline $\begin{array}{l}\text { Excessive } \\
\text { protecting }\end{array}$ & -.07 & -.10 & -.02 & $.17^{*}$ & .14 & $.21 *$ & .04 & .02 & .05 & -.02 & -.03 & -.002 \\
\hline$R_{\text {corrected }}^{2}$ & $.18^{* * * *}$ & $.23 * * *$ & $.20^{* * *}$ & $.16^{* * *}$ & $.16^{* * *}$ & $.16^{* * *}$ & $.31^{* *}$ & $.35^{* * *}$ & $.30 * * *$ & $10^{* * *}$ & $.07 * *$ & $.134 * * *$ \\
\hline$\Delta R^{2}$ & $.02 *$ & $.04 *$ & .01 & $.14 * * *$ & $.13^{* * *}$ & $.15^{* * *}$ & $.06^{* *}$ & $.13 * * *$ & .01 & .10 & .01 & .003 \\
\hline
\end{tabular}

${ }^{*} p<.05 ;{ }^{* *} p<.01 ;{ }^{* * *} p<.001$. 
In this model, what significantly and positively predicted encouragement of nonconformism were the dimensions of excessive requirements ( $\beta=.48 ; p<0,001)$ and excessive protecting $(\beta=.17 ; p<0,05)$, while incocnsistency predicted it negatively $(\beta=-.39 ; p<0,001)$. Overall, the destructive parenting style was explained by the total of $14 \%$ of the variance of results on this scale, whereas the constructive parenting style was explained by as little as $2 \%$.

The structure of relations between the components of parenting style and encouragement to experience novelty and variety was different for mothers and fathers. In the case of mothers, the dimension of acceptance ( $\beta$ $=.47 ; p<0,001)$ was the only significant predictor, whereas in the case of fathers, it was both acceptance $(\beta=$ $.21 ; p<0,05)$ and autonomy $(\beta=.26 ; p<0,05)$. For both mothers and fathers, constructive parenting style was explained by $19 \%$ of the variance of encouragement to experience novelty.

Relations between the components of parenting style and encouragement of nonconformism also differed slightly per parents' gender. In the case of mothers, the dimensions of excessive requirements $(\beta=.53 ; p$ $<0,001)$ and inconsistency $(\beta=-.49 ; p<0,001)$ proved to be significant predictors of encouragement of nonconformism, whereas in the case of fathers, it was excessive requirements $(\beta=.40 ; p<0,001)$, inconsistency $(\beta=-.23 ; p<0,05)$, as well as excessive protecting $(\beta=.21 ; p<0,05)$. Components of the destructive parenting style made it possible to explain the total of $14 \%$ of the variance of encouragement of nonconformism in the case of mothers and $15 \%$ in the case of fathers.

Parents' gender differences also appeared in the structure of relations between parenting style and support of perseverance in creative efforts in the parent-child relationships. For mothers, the dimensions of acceptance $(\beta=.39 ; p<0,001)$ as well as inconsistency $(\beta=-.28 ; p<0,05)$ proved to be significant predictors of this type of behavior, while in the case of fathers, these were the dimensions of acceptance $(\beta=.35 ; p<0,001)$ as well as autonomy $(\beta=.26 ; p<0,05)$. The tested models explained the total of $35 \%$ of the variance of support of perseverance in creative efforts among mothers and $29 \%$ among fathers.

In the case of mothers, the dimension of acceptance $(\beta=.23 ; p<0,05)$ proved to be the only predictor only predictor of encouragement to fantasize, while in the case of fathers, it was the dimension of autonomy ( $\beta=$ $.28 ; p<0,01)$. Whereas in the group of mothers, the constructive parenting style explained the total of $6 \%$ of the variance of encouragement to fantasize, in the case of fathers, the percentage of explained variance was almost twice higher and reached $13 \%$. 


\section{Discussion}

This study sheds new light on how dimensions of parenting style matter for climate for creativity in the parentchild relationship. Specifically, we examined how parental acceptance of a child and autonomy granting (defined as a constructive style) are linked to encouragement to experience novelty and variety, encouragement of nonconformism, support of perseverance in creative efforts, and encouragement to fantasize. We also examined whether the level of parents' vividness of mental imagery, which we operationalized as a parent's creative potential, is related to the factors of the climate for creativity in the parent-child relationship. Finally, we examined parents' gender differs in the explanation of relationships between the parental style and the climate for creativity in the home environment.

Similar to previous research (e.g. Fan \& Zhang, 2014; Rathunde, 1996; Tennent \& Berthelsen, 1997), the constructive parenting style characterized by acceptance and autonomy granting was linked with creative home environment. The results revealed a positive relationship between parental acceptance of a child and encouragement to experience novelty (H1a), support of perseverance in creative efforts (H3a), and encouragement to fantasize (H4a) in the parent-child relationship. Likewise, parental autonomy granting was positively related to the encouragement to experience novelty and variety (H1b), support of perseverance in creative efforts (H3b), and encouragement to fantasize (H4b) in the parent-child relationship. Also, the constructive parenting style consisting of the dimensions of acceptance of a child and autonomy granting explained much more of the variance than the destructive parenting style in the case of three of four factors of the climate for creativity in the parent-child relationships, i.e. (1) encouragement to experience novelty and variety, (2) support of perseverance in creative efforts, and (3) encouragement to fantasize. These findings demonstrate the important and powerful role of the family as a context of children's creativity development. It has been proven that parent-child relationship that manifest themselves through creating a home environment where a child may be autonomous, unconventional, curious, and open-minded are linked with nurturing children's creativity (Pugsley \& Acar, 2018). However, in our study, we did not examine the development of children's creativity in relation to parental behaviors that support their creative potential. Thus, more longitudinal designs need to be done to examine the relationships between constructive parenting style and climate for creativity in the parent-child relationships, as well as whether and to what extent this type of parenting practice impacts on children's creativity development. Moreover, future research should also investigate broader analyses of the interactions among specific factors in the ecological systems around children, such as family-school partnerships as an essential and effective way to promote children's development (Yamauchi, Ponte, Ratliffe, \& Traynor, 2017), including their creativity (Kemple \& Nissenberg, 2000). 
Contrary to predictions, no significant relationships were found between parental autonomy of a child and encouragement of nonconformism as one of the factors of the climate for creativity in the home environment (H2a), as well as parental autonomy granting and encouragement of nonconformism (H2b). This may be due to the parents' understanding of nonconformism as an indicator of children's creative potential or insufficient sensitivity of the tool that was used to assess this personal trait in childhood. When taking into account the age of children concerned by the data collected in the survey, perhaps in parents' perception, children's nonconformism defined as a tendency to choose unconventional behavior and challenge existing norms (Kwaśniewska et al., 2018) is not related with support for autonomy and creative potential, but for rebellion and relatively low social competence, which in fact makes it harder to effectively function in society (see "rebellious creativity", Karwowski \& Jankowska, 2016). For this reason, participants may have responded to questions in socially desirable ways. Perhaps independent behavior of children, defined as non-conformism related to creativity, should be re-examined. For this purpose, additional experimental or observational studies should be carried out, but deepened by interviews with parents about conventional social rules, including their understanding of and necessity for these rules by their children. It should also be noted that not only the parents' definition of nonconformity may depend on the age of their children. Moreover, in the present study, only parental self-report measures were used to assess parenting behavioral outcomes. Children's perspective on parenting practices may be quite different, although a significant convergence between a child and parent reports on parenting dimensions (among others supporting) has been established in middle childhood (Kuppens, Grietens, Onghena, \& Michiels, 2009). Nonetheless, it would be beneficial in future studies to include a multiple informant approach when identifying parenting behaviors, also in different age groups.

As for the creative potential of parents, the present study has found supporting evidence for a positive (but weak) correlation both between the factors of climate for creativity in parent-child relationships and the dimensions of constructive parenting style. It seems that the high degree of vividness of mental imagery is not the most important for nurturing children's creativity, but the positive correlations between this variable and the dimensions of constructive parenting style, (i.e. parental acceptance and autonomy granting), as well as all factors of the climate for creativity in parent-child relationships suggest that parents' creative potential can be important for creating an environment that stimulates children's creativity. In this sense, our findings are somewhat in line with expectations we have of teachers. According to them, we assume that students' creativity is developed best by creative teachers (Rejskind, 2000). Perhaps it would be appropriate to analyze not only the creative potential (e.g. level of creative abilities of parents or personality traits related to creativity), but also 
creative achievement that refers to actual real-life creative accomplishments (Carson, Peterson, \& Higgins, 2005) or parents' creative mindsets, i.e. beliefs about the stable versus malleable character and the nature of creativity (Karwowski, 2014), and their links with parents' parenting styles and fostering creativity at home. This would be an interesting question for future research to address.

The role of parents' gender in the structure of the relationships between the dimensions of a constructive parenting style and factors of the climate for creativity in parent-child relationship is more complex to interpret. More than fathers, the examined mothers were characterized by significantly higher intensity of acceptance of a child, which is very often used in defining the emotional warmth dimension (Skinner et al., 2005). Only this one significant difference between fathers and mothers was found in the analyzed variables. This result is consistent with previous findings (e.g. John et al., 2013; Russell \& Russell, 1987) and one explanation of this may be that mothers spend more time with their children than fathers do (e.g. Craig, 2006; McBride \& Mills, 1993; Mehall et al., 2009) and thus they build warmer, accepting relationships. An alternative explanation is that the father's acceptance is more conditional than the mother's (Forehand \& Nousiainen, 1993) and for this reason, we noted lower level of its occurrence. Importantly, the structure of the relationship between the components of a constructive parenting style and factors of climate for creativity in parent-child relationship was different for mothers and fathers. Perhaps one of the most important findings was that fatherly autonomy, but not motherly, was a significant predictor of three out of four factors of the climate for creativity in parent-child relationship, i.e. encouragement to experience novelty and variety, support of perseverance in creative efforts, and encouragement to fantasize. In the group of mothers, the dimension of acceptance turned out to be predictive for these elements of the creative climate in the environment. These findings suggest that autonomy granting may be a crucial aspect of fathers' parenting in the context of fostering children's creativity, whereas acceptance in the case of mothers. According to the gender schema theory (Bem, 1981), females tend to exhibit higher levels of expressiveness, sensitivity, and affection, and males generally exhibit higher instrumentality (Wood \& Eagly, 2002). Consequently, it is possible that mothers may adopt a warmer, supportive style to promote children's creativity, whereas fathers a more goal-oriented style, that focuses on posing challenges. These differences are likely due to gender-specific behaviors and should be investigated in future research.

\section{Limitations}

Our study is not void of limitations. First, it is important to emphasize that it was conducted solely on parents. Because of this, we are not certain whether the dimensions of parenting styles and factors of the climate for creativity in parent-child relationships we controlled really exert positive influence on the development of 
children's creativity. Because in this study we did not control the level of children's creativity, we can only predict that parental behaviors we analyzed are conducive to children's creativity, as previous studies indicated (see Harrington, Block, \& Block, 1987). This is why we recommend that in future such studies include children's creativity levels and are longitudinal. It is only then that it will truly be possible to indicate that the dimensions of parenting styles and factors of the climate for creativity in parent-child relationships we analyzed do influence development of children's creative potential, or contribute to their mature creative achievements.

Secondly, unfortunately, we do not know how examined parents understand the notion of creativity, which could be critical for the activities they undertake to support their children's creative potential. It applies both to their convictions about whether children's creative potential is invariable (fixed mindset) or possible to be stimulated (growth mindset) (see Karwowski, 2014; Kaufman \& Beghetto, 2013) and to the personality characteristic of a creative child, which may be of significant importance for the results we obtained. For instance, recent studies by Gralewski (2019) show that teachers include students' independence among personality traits of creative students, but we are not certain that this trait is of importance also to parents and if yes then how they interpret it. Such analyses could help understand the lack of relation between constructive parenting style and encouragement of nonconformism as one of the factors of the climate for creativity in the home environment.

Finally, it is important to note that the dimensions of parenting styles we analyzed correlated. Even though in our study the level of multicollinearity was acceptable, it could potentially influence estimation of standardized regression coefficients. This is why we tested our hypotheses in two ways - by using bivariate correlations and hierarchical regression analyses. Moreover, in consideration of mutual correlation of variables that form constructive and destructive parenting styles, we conducted regression analyses in two blocks, which made it possible for us to assess the percentage of explained variance $\left(\mathrm{R}^{2}\right)$ for each of these styles in relation to the factors of climate for creativity in the home environment, and hence to indicate which of these styles is of greater importance to the parents.

\section{Conclusion}

In summary, present study provides new information about how parenting styles are linked to the climate for creativity in families with children aged 6-12. Although future studies are warranted to validate these findings, we found that constructive parenting style (i.e. parental acceptance of a child and autonomy granting) predicted encouragement to experience novelty and variety, support of perseverance in creative efforts, and encouragement to fantasize in the parent-child relationship, and patterns of these relations were different for mothers and fathers. 
Thus, our study may be the first step in explaining the role of parental behavior for children's creativity development though creating a climate for creativity in the home environment.

\section{References}

Abuhassàn, A., \& Bates, T. C. (2015). Grit: Distinguishing effortful persistence from conscientiousness. Journal of Individual Differences, 36, 205-214. https://doi.org/10.1027/1614-0001/a000175

Aiken, L. S., \& West, S. G. (2001). Multiple regression: Testing and interpreting interactions. Newbury Park, CA: Sage.

Albert, R. S., \& Runco, M. A. (1989). Independence and the creative potential of gifted and exceptionally gifted boys. Journal of Youth and Adolescence, 18, 221-230. https://doi.org/10.1007/bf02139037

Amabile, T. (2012). Componential theory of creativity. Boston: Harvard Business School.

Amabile, T. M. (1983). The social psychology of creativity: A componential conceptualization. Journal of Personality and Social Psychology, 45(2), 357-376. https://doi.org/10.1037/0022-3514.45.2.357

Batey, M., \& Furnham, A. (2006). Creativity, intelligence, and personality: A critical review of the scattered literature. Genetic, Social, and General Psychology Monographs, 132(4), 355-429. https://doi.org/10.3200/mono.132.4.355-430

Baumrind, D. (1967). Child care practices anteceding three patterns of preschool behavior. Genetic Psychology Monographs, 75(1), 43-88.

Beghetto, R. A., \& Kaufman, J. C. (2007). Toward a broader conception of creativity: A case for mini-c creativity. Psychology of Aesthetics, Creativity and the Arts, 1, 73-79. https://doi.org/10.1037/19313896.1.2.73

Bem, S. (1981). Gender schema theory: A cognitive account of sex typing. Psychological Review, 88, 354-364. https://doi.org/10.1037/0033-295x.88.4.354

Bradley, R. H., \& Corwyn, R. F. (2004). "Family process" investments that matter for child well-being. In A. Kalil \& T. DeLeire (Eds.), Monographs in parenting. Family investments in children's potential: Resources and parenting behaviors that promote success (p. 1-32). Lawrence Erlbaum Associates Publishers.

Burton, L. J. (2003). Examining the relation between visual imagery and spatial ability tests. International Journal of Testing, 3(3), 277-291. https://doi.org/10.1207/s15327574ijt0303_6

Campos, A., \& Pérez-Fabello, M. J. (2009). Psychometric quality of a revised version Vividness of Visual Imagery Questionnaire. Perceptual and Motor Skills, 108(3), 798-802.

https://doi.org/10.2466/pms.108.3.798-802

Carson, S. H., Peterson, J. B., \& Higgins, D. M. (2005). Reliability, validity, and factor structure of the Creative Achievement Questionnaire. Creativity Research Journal, 17(1), 37-50.

https://doi.org/10.1207/s15326934crj1701_4

Craft, A. (2006). Creativity across the primary curriculum: Framing and developing practice. London: Routledge.

Craig, L. (2006). Does father care mean fathers share?: A comparison of how mothers and gathers in intact families spend time with children. Gender \& Society, 20(2), 259-281.

https://doi.org/10.1177/0891243205285212 
Craig, L., \& Mullan, K. (2011). How mothers and fathers share childcare. A cross-national time use comparison. American Sociological Review, 76, 834-861. https://doi.org/10.1177/0003122411427673

Cropley, A. J. (1967). Creativity. London: Longman.

D’Angiulli, A., \& Reeves, A. (2007). The relationship between self-reported vividness and latency during mental size scaling of everyday items: Phenomenological evidence of different types of imagery. The American Journal of Psychology, 120(4), 521. https://doi.org/10.2307/20445424

Darling, N., \& Steinberg, L. (1993). Parenting style as context: An integrative model. Psychological Bulletin, 113(3), 487-496. https://doi.org/10.1037/0033-2909.113.3.487

Deng, L., Wang, L., \& Zhao, Y. (2016). How creativity was affected by environmental factors and individual characteristics: A cross-cultural comparison perspective. Creativity Research Journal, 28(3), 357-366. https://doi.org/10.1080/10400419.2016.1195615

Ekvall, G. (1996). The organizational climate for creativity and innovation. European Journal of Work and Organizational Psychology, 5, 105-123.

Ekvall, G., \& Ryhammar, L. (1998). Leadership style, social climate and organizational outcomes: A study of a Swedish University College. Creativity and Innovation Management, 7(3), 126-130. https://doi.org/10.1111/1467-8691.00100

Erikson, E. H. (1963). Childhood and society. New York: Norton.

Fan, J., \& Zhang, L. (2014). The role of perceived parenting styles in thinking styles. Learning and Individual Differences, 32, 204-211. https://doi.org/10.1016/j.lindif.2014.03.004

Fijałkowska, D., \& Bielawska-Batorowicz, E. (2019). A longitudinal study of parental attachment: Pre- and postnatal study with couples. Journal of Reproductive and Infant Psychology, 1-14. https://doi.org/10.1080/02646838.2019.1665172

Forehand, R., \& Nousiainen, S. (1993). Maternal and paternal parenting: Critical dimensions in adolescent functioning. Journal of Family Psychology, 7(2), 213-221. https://doi.org/10.1037/0893-3200.7.2.213

Foster, J. F. (2015). Not now, maybe later: Helping children overcome procrastination. Tucson, AZ: Great Potential Press.

Furman, A. (1998). Teacher and pupil characteristics in the perception of the creativity of classroom climate. Journal of Creative Behavior, 32, 258-277. https://doi.org/10.1002/j.2162-6057.1998.tb00821.x

Gardner, K. G., \& Moran, J. D. (1990). Family adaptability, cohesion, and creativity. Creativity Research Journal, 3(4), 281-286. https://doi.org/10.1080/10400419009534361

Glăveanu, V. P., Karwowski, M., Jankowska, D. M., \& de Saint-Laurent, C. (2017). Creative imagination. In T. Zittoun \& V. P. Glăveanu (Eds.), The Oxford handbook of imagination and culture (pp. 61-86). Oxford: Oxford University Press.

Goertzel, V., Goertzel, M. G., Goertzel, T. G., \& Hansen, A. (2004). Cradles of eminence: Childhoods of more than 700 famous men and women. Scottsdale, AZ, US: Great Potential Press, Inc.

González, M. A., Campos, A., \& Pérez, M. J. (1997). Mental imagery and creative thinking. The Journal of Psychology, 131(4), 357-364.

Gralewski, J. (2019). Teachers' beliefs about creative students' characteristics: A qualitative study. Thinking Skills and Creativity, 31, 138-155. https://doi.org/10.1016/j.tsc.2018.11.008 
Grolnick, W. S., Gurland, S. T., DeCourcey, W., \& Jacob, K. (2002). Antecedents and consequences of mothers' autonomy support: An experimental investigation. Developmental Psychology, 38(1), 143-155. https://doi.org/10.1037/0012-1649.38.1.143

Grossmann, K., Grossmann, K. E., Fremmer-Bombik, E., Kindler, H., Scheuerer-Englisch, H., \& Zimmerman, P. (2002). The uniqueness of the child-father attachment relationship: Fathers' sensitive and challenging play as the pivotal variable in a 16-year longitudinal study. Social Development, 11, 307-331.

https://doi.org/10.1111/1467-9507.00202

Guilford, J. P. (1967). The nature of human intelligence. New York: McGraw-Hill.

Gute, G., Gute, D. S., Nakamura, J., \& Csikszentmihályi, M. (2008). The early lives of highly creative persons: The influence of the complex family. Creativity Research Journal, 20(4), 343-357. https://doi.org/10.1007/978-94-017-9085-7_18

Hair, J. F., Jr., Anderson, R. E., Tatham, R. L., \& Black, W. C. (1995). Multivariate data analysis (3rd ed). New York: Macmillan.

Harrington, D. M. (1999). Conditions and settings environment (pp. 403-412). In: M. A. Runco \& S. R. Pritzker (Eds.), Encyclopedia of creativity. San Diego, CA: Academic Press.

Harrington, D. M., Block, J. H., \& Block, J. (1987). Testing aspects of Carl Rogers's theory of creative environments: Child-rearing antecedents of creative potential in young adolescents. Journal of Personality and Social Psychology, 52(4), 851-856. https://doi.org/10.1037/0022-3514.52.4.851

Helson, R., Roberts, B., \& Agronick, G. (1995). Enduringness and change in creative personality and the prediction of occupational creativity. Journal of Personality and Social Psychology, 69, 1173-1183. https://doi.org/10.1037/0022-3514.69.6.1173

Howe, M. J. A. (1999). Prodigies and creativity. In R. J. Sternberg (Ed.), Handbook of creativity (pp. 431-446). Cambridge: Cambridge University Press.

Hunter, S. T., Bedell, K. E., \& Mumford, M. D. (2007). Climate for creativity: A quantitative review. Creativity Research Journal, 19(1), 69-90. https://doi.org/10.1037/e518572013-253

Jankowska, D. M., \& Karwowski, M. (2019). Family factors and development of creative thinking. Personality and Individual Differences, 142, 202-206. https://doi.org/10.1016/j.paid.2018.07.030

Jankowska, D. M., \& Omelańczuk, I. (2018). Potential mechanisms underlying the impact of imaginative play on socio-emotional development in childhood. Creativity: Theories-Research-Application, 5(1), 84-103. https://doi.org/10.1515/ctra-2018-0006

John, A., Halliburton, A., \& Humphrey, J. (2013). Child--mother and child-father play interaction patterns with preschoolers. Early Child Development and Care, 183(3-4), 483-497. https://doi.org/10.1080/03004430.2012.711595

Kallestad, J. H., Olweus, D., \& Alsaker, F. (1998). School climate reports from Norweginan Teachers: A methodological and substantive study. School Effectiveness and School Improvement, 9(1), 70-94. https://doi.org/10.1080/0924345980090104

Karnes, M. B., Shwedel, A. M., \& Steinberg, D. (1984). Styles of parenting among parents of young gifted children. Roeper Review, 4, 232-235. https://doi.org/10.1080/02783198409552824

Karwowski, M. (2011). The creative mix? : Teacher`s creative leadership, school creative climate, and students` creative self-efficacy. Chowanna, 1, 25-43. 
Karwowski, M. (2014). Creative mindsets: Measurement, correlates, consequences. Psychology of Aesthetics, Creativity, and the Arts, 8(1), 62-70. https://doi.org/10.1037/a0034898

Karwowski, M., \& Jankowska, D. (2016). Four faces of creativity at school. In R. A. Beghetto \& J. C. Kaufman (Eds.), Nurturing creativity in the classroom (pp. 337-354). New York, NY: Cambridge University Press.

Kaufman, J. C., \& Beghetto, R. A. (2013). In praise of Clark Kent: Creative metacognition and the importance of teaching kids when (not) to be creative. Roeper Review, 35, 155-165.

https://doi.org/10.1080/02783193.2013.799413

Kawabata, Y., Alink, L. R. A., Tseng, W.-L., van Ijzendoorn, M. H., \& Crick, N. R. (2011). Maternal and paternal parenting styles associated with relational aggression in children and adolescents: A conceptual analysis and meta-analytic review. Developmental Review, 31(4), 240-278.

https://doi.org/10.1016/j.dr.2011.08.001

Kemple, K. M., \& Nissenberg, S. A. (2000). Nurturing creativity in early childhood education: Families are part of it. Early Childhood Education Journal, 28(1), 67-71.

Kihlstrom, J. F., Glisky, M. L., Peterson, M. A., Harvey, E. M., \& Rose, P. M. (1991). Vividness and control of mental imagery: A psychometric analysis. Journal of Mental Imagery, 15(3-4), 133-142

Kim, K. (2016). The creativity challenge: How we can recapture American innovation. Amherst, NY: Prometheus Books.

Koestner, R., Walker, M., \& Fichman, L. (1999). Childhood parenting experiences and adult creativity. Journal of Research in Personality, 33(1), 92-107. https://doi.org/10.1006/jrpe.1998.2240

Kromelow, S., Harding, C., \& Touris, M. (1990). The role of the father in the development of stranger sociability during the second year. American Journal of Orthopsychiatry, 60, 521-530.

https://doi.org/10.1037/h0079202

Kuppens, S., Grietens, H., Onghena, P., \& Michiels, D. (2009). Measuring parenting dimensions in middle childhood: Multitrait-multimethod analysis of child, mother, and father ratings. European Journal of Psychological Assessment, 25, 133-140. https://doi.org/10.1027/1015-5759.25.3.133

Kwaśniewska, J. M., Gralewski, J., Witkowska, E. M., Kostrzewska, M., \& Lebuda, I. (2018). Mothers' personality traits and the climate for creativity they build with their children. Thinking Skills and Creativity, 27, 13-24. https://doi.org/10.1016/j.tsc.2017.11.002

Kwaśniewska, J. M., \& Lebuda, I. (2017). Balancing between roles and duties - The creativity of mothers. Creativity. Theories - Research - Applications, 4(1), 137-158. https://doi.org/10.1515/ctra-2017-0007

LeBoutillier, N., \& Marks, D. F. (2003). Mental imagery and creativity: A meta-analytic review study. British Journal of Psychology, 94, 29-44. https://doi.org/10.1348/000712603762842084

Lebuda, I., \& Csikszentmihalyi, M. (2020). All you need is love: The importance of partner and family relations to highly creative individuals' well-being and success. The Journal of Creative Behavior, 54(1), 100-114. https://doi.org/10.1002/jocb.348

Lim, S., \& Smith, J. (2008). The structural relationships of parenting style, creative personality, and loneliness. Creativity Research Journal, 20(4), 412-419. https://doi.org/10.1080/10400410802391868

Maccoby, E. E., \& Martin, J. A. (1983). Socialization in the context of the family: Parent-child interaction. In P. H. Mussen (Ed.) \& E. M. Hetherington (Vol. Ed.), Handbook of child psychology: Vol. 4. Socialization, personality, and social development (4th ed., pp. 1-101). New York: Wiley. 
Marks, D. F. (1973). Visual imagery differences in the recall of pictures. British Journal of Psychology, 64, 17 24. https://doi.org/10.3758/bf03211175

McAvinue, L. P., \& Robertson, I. H. (2007). Measuring visual imagery ability: A review. Imagination, Cognition and Personality, 26(3), 191-211. https://doi.org/10.2190/3515-8169-24j8-7157

McBride, B. A., \& Mills, G. (1993). A comparison of mother and father involvement with their preschool age children. Early Childhood Research Quarterly, 8(4), 457-477. https://doi.org/10.1016/s08852006(05)80080-8

Mehall, K. G., Spinrad, T. L., Eisenberg, N., \& Gaertner, B.M. (2009). Examining the relations of infant temperament and couples' marital satisfaction to mother and father involvement: A longitudinal study. Fathering, 7(1), 23-48. https://doi.org/10.3149/fth.0701.23

Mehrinejad, S. A., Rajabimoghadam, S., \& Tarsafi, M. (2015). The relationship between parenting styles and creativity and the predictability of creativity by parenting styles. Procedia - Social and Behavioral Sciences, 205, 56-60. https://doi.org/10.1016/j.sbspro.2015.09.014

Michel, M., \& Dudek, S. Z. (1991). Mother-child relationships and creativity. Creativity Research Journal, 4(3), 281-286. https://doi.org/10.1080/10400419109534400

Miller, B. C., \& Gerard, D. (1979). Family influences on the development of creativity in children: An integrative review. The Family Coordinator, 28(3), 295. https://doi.org/10.2307/581942

Nickerson, R. S. (1999). Enhancing creativity. In R. J. Sternberg (Ed.), Handbook of creativity (pp. 392-410). Cambridge, UK Cambridge University Press.

Olszewski, P., Kulieke, M. J., \& Buescher, T. (1987). The influence of the family environment on the development of talent: A literature review. Journal for the Education of the Gifted, 11(1), 6-28. https://doi.org/10.1177/016235328701100102

Palmiero, M., Cardi, V., \& Belardinelli, M. O. (2011). The role of vividness of visual mental imagery on different dimensions of creativity. Creativity Research Journal, 23(4), 372-375. https://doi.org/10.1080/10400419.2011.621857

Pang, W., Lu, Y., Long, H., Wang, Q., \& Lin, L. (2020). Three-generational families: Are they beneficial to Chinese children's creativity? Thinking Skills and Creativity, 35, 100623. https://doi.org/10.1016/j.tsc.2019.100623

Plopa, M. (2008). Skala postaw rodzicielskich. Wersja dla rodziców. [The parental attitude scale. The version for parents] Warszawa: Pracownia Testów Psychologicznych Polskiego Towarzystwa Psychologicznego.

Power, T. G. (2013). Parenting dimensions and styles: A brief history and recommendations for future research. Childhood Obesity, 9(s1), S-14-S-21. https://doi.org/10.1089/chi.2013.0034

Puchalska-Wasyl, M. M., \& Jankowski, T. (2020). Do internal dialogues in young adults depend on motherfather incongruence in parental attitudes assessed retrospectively? Journal of Family Issues, 41(5), 667-691. https://doi.org/10.1177/0192513x19881773

Pugsley, L., \& Acar, S. (2018). Supporting creativity or conformity? Influence of home environment and parental factors on the value of children's creativity characteristics. The Journal of Creative Behavior. https://doi.org/10.1002/jocb.393 
Rank, J., Pace, V. L., \& Frese, M. (2004). Three avenues for future research on creativity, innovation, and initiative. Applied Psychology: An International Review, 53, 518-528. https://doi.org/10.1111/j.14640597.2004.00185.x

Rathunde, K. (1996). Family context and talented adolescents' optimal experience in school-related activities. Journal of Research on Adolescence, 6, 605-628.

Rejskind, F. G. (1982). Autonomy and creativity in children. Journal of Creative Behavior, 16, 58-67. https://doi.org/10.1002/j.2162-6057.1982.tb00322.x

Rejskind, F. G. (2000). TAG teachers: Only the creative need apply. Roeper Review, 22, 153-157. https://doi.org/10.1080/02783190009554023

Robson, S., \& Rowe, V. (2012). Observing young children's creative thinking: Engagement, involvement and persistence. International Journal of Early Years Education, 20(4), 349-364. https://doi.org/10.1080/09669760.2012.743098

Rogers, C. R. (1954). Toward a theory of creativity. ETC: A Review of General Semantics, 11, 249 -260.

Runco, M. A. (2003). Education for creative potential. Scandinavian Journal of Educational Research, 47, 317 324.

Russ, S. (2004). Play in child development and psychotherapy. Toward empirically supported practice. New Jersey-London: Lawrence Erlbaum Associates.

Russ, S. W., Robins, A. L., \& Christiano, B. A. (1999). Pretended play: Longitudinal prediction of creativity and affect in fantasy in children. Creativity Research Journal, 12, 129- 139. https://doi.org/10.1207/s15326934crj1202_5

Russell, G., \& Russell, A. (1987). Mother-child and father-child relationship in middle childhood. Child Development, 58, 1573-1585. https://doi.org/10.2307/1130696

Sayer, L. C., Bianchi, S. M., \& Robinson, J. P. (2004). Are parents investing less in children? Trends in mothers' and fathers' time with children. American Journal of Sociology, 110(1), 1-43. https://doi.org/10.1086/386270

Simons, R. L., Whitbeck, L. B., Conger, R. D., \& Melby, J. N. (1990). Husband and wife differences in determinants of parenting: A social learning and exchange model of parental behavior. Journal of Marriage and the Family, 52(2), 375-392. https://doi.org/10.2307/353033

Skinner, E., Johnson, S., \& Snyder, T. (2005). Six dimensions of parenting: A motivational model. Parenting: Science and Practice, 5(2), 175-235. https://doi.org/10.1207/s15327922par0502_3

Stavridou, A., \& Furnham, A. (1996). The relationship between psychoticism, trait-creativity and the attentional mechanism of cognitive inhibition. Personality and Individual Differences, 21(1), 143-153. https://doi.org/10.1016/0191-8869(96)00030-х

Tennent, L., \& Berthelsen, D. (1997). Creativity: What does it mean in the family context? Journal of Australian Research in Early Childhood Education, 1, 91-104.

Torrance, E. P. (1965). Rewarding classroom behaviour. Experiments in the classroom. Englewood Cliffs, NJ: Prentice Hall.

Treffinger, D. J. (1980). Encouraging creative learning for the gifted and talented. Ventura, CA: Ventura County Schools/LTI.

Vygotsky, L. S. (1930/2004). Imagination and creativity in childhood. Journal of Russian and East European Psychology, 42, 7-97. 
Wittkowski, A., Garrett, C., Calam, R., \& Weisberg, D. (2017). Self-report measures of parental self-efficacy: A systematic review of the current literature. Journal of Child and Family Studies, 26(11), 2960-2978. https://doi.org/10.1007/s10826-017-0830-5

Wood, W., \& Eagly, A. H. (2002). A cross-cultural analysis of the behavior of women and men: Implications for the origins of sex differences. Psychological Bulletin, 128, 699-727. https://doi.org/10.1037/00332909.128.5.699

Wright, C \& Wright, S (1986). A conceptual framework for examining the family's influence on creativity. Family Perspective, 20(2), 127-136.

Yamauchi, L. A., Ponte, E., Ratliffe, K. T., \& Traynor, K. (2017). Theoretical and conceptual frameworks used in research on family-school partnerships. School Community Journal, 27(2), 9-34. 